\title{
Solos e vegetação nativa remanescente no Município de Campinas
}

\author{
Ivan Carlos de Moraes Ferreira(1), Ricardo Marques Coelho(1), Roseli Buzanelli Torres ${ }^{(1)}$ e Luís Carlos Bernacci(1) \\ (1)Instituto Agronômico, Caixa Postal 28, CEP 13001-970 Campinas, SP. E-mail: icmf@hotmail.com, rmcoelho@iac.sp.gov.br, \\ rbtorres@iac.sp.gov.br, bernacci@iac.sp.gov.br
}

\begin{abstract}
Resumo - O objetivo deste trabalho foi identificar atributos e classes de solos associados à ocorrência de remanescentes de cerrado e de floresta nativa em Campinas, SP, e identificar espécies indicadoras desses ambientes. Vinte e sete fragmentos de vegetação nativa foram estudados. Foi realizada a caracterização morfológica, classificação e coleta do solo para análises, bem como o levantamento florístico-fitossociológico do estrato arbóreo. A análise de correspondência canônica identificou as variáveis mais bem correlacionadas com a distribuição das espécies e identificou 15 variáveis que explicaram $31 \%$ da variância nos dois primeiros eixos. A classificação dos solos discriminou as fitofisionomias estudadas, Argissolos associados às matas e Latossolos aos cerrados, indício de que baixa fertilidade, baixa retenção de água e drenagem acentuada do solo favorecem o estabelecimento de cerrado. Parâmetro "n” da curva de retenção de água, densidade, $\mathrm{H}+\mathrm{Al}, \mathrm{Ca}, \mathrm{Al}, \mathrm{K}$ e $\mathrm{Mg}$ trocáveis, macroporos e matéria orgânica do solo foram os atributos dos solos mais efetivos nessa diferenciação fitofisionômica. A barreira química imposta pelo excesso de Al e deficiência de Ca no horizonte $\mathrm{B}$ e a baixa retenção de água nos solos sob cerrado favorecem as espécies Luehea grandiflora, Persea willdenovii, Xylopia aromatica e Erythroxylum daphnites, abundantes e exclusivamente encontradas nos fragmentos de cerrado.
\end{abstract}

Termos para indexação: associações solo-vegetação, cerrado, água do solo, toxicidade de alumínio.

\section{Soil and native vegetation remnant in Campinas, SP, Brazil}

\begin{abstract}
The objective of this work was to identify soil attributes and classes associated to the occurrence of forest and tropical savannah remnants in Campinas, SP, Brazil. Twenty seven native vegetation fragments were studied. Soil morphological, chemical, and physical characterization were carried out, along with floristicphytosociological survey of the tree stratum. Canonic correspondence analysis identified variables better correlated with plant species distribution. Fifteen environment variables explained $31 \%$ of the variance of the first two axes. Soil classes at the Brazilian System of Soil Classification discriminated the studied vegetation: soils with argillic B horizons were more associated to forests, and soils with oxic B horizons, low fertility and good drainage were associated to tropical savannahs. Low fertility, low water retention and good drainage benefit cerrado vegetation establishment. Multivariate analysis identified $n$ parameter of the water retention curve, bulk density, exchangeable $\mathrm{H}+\mathrm{Al}, \mathrm{Ca}, \mathrm{Al}, \mathrm{K}$ and $\mathrm{Mg}$, macropores and soil organic matter as the most effective soil attributes to plant physiognomy differentiation. The chemical barrier imposed by excess aluminum and calcium deficiency, at B horizon, as well as low water retention in soils under savannah vegetation benefit Luehea grandiflora, Persea willdenovii, Xylopia aromatica and Erythroxylum daphnites, abundant and exclusive species on savannah fragments.
\end{abstract}

Index terms: soil-vegetation associations, tropical savannah, soil water, aluminum toxicity.

\section{Introdução}

A vegetação nativa remanescente no Município de Campinas é constituída por matas, cerrado e pequenos trechos de vegetação rupícula (Santin, 1999). A presença de formações vegetais tão diferenciadas numa mesma região, com ampla diversidade de espécies, demonstra a importância ecológica dessa área. Os fragmentos de vegetação nativa cobrem $2,6 \%$ do território do Município (Kronka et al., 2005).

O conhecimento da vegetação nativa remanescente pode auxiliar na manutenção e aproveitamento da biodiversidade desses ecossistemas que, além do seu valor intrínseco, são essenciais nos ciclos biológicos e 
hidrológicos, assim como eficientes reguladores térmicos e agentes de amenização paisagística. Nas áreas urbanas, essas funções são exercidas quase que exclusivamente por remanescentes vegetais, em especial pelos de vegetação nativa.

Características climáticas regionais, que conduzem a um regime hídrico de solo ústico (Soil Survey Staff, 1999), ou seja, solo seco (potencial matricial abaixo de $-1.500 \mathrm{kPa}$ ) por mais de 90 dias cumulativos, associadas à ação do fogo, inundação periódica, baixo nível de nutrientes e excesso de alumínio trocável $\left(\mathrm{Al}^{3+}\right)$, são tidas como responsáveis pelo predomínio dos cerrados em relação a outras formações vegetais em sua regiãonúcleo de ocorrência (Haridasan, 2000). Características climáticas regionais, porém, não são suficientes para explicar a ocorrência de fragmentos de vegetação de cerrado em regiões de pedoclima mais úmido (údico) em meio à vegetação nativa predominantemente florestal. A teoria dos refúgios florestais (Haffer \& Prance, 2002) procura explicar a distribuição fragmentada do cerrado nessas regiões (Viadana, 2002). Ela não explica, contudo, como seria o ambiente de refúgio nos cerrados, informação essencial para recuperação e preservação de fragmentos dessa formação vegetal em áreas em que as formações clímax esperadas são florestais.

Os estudos que buscam relacionar determinada fisionomia vegetal a fatores ambientais se concentram principalmente na relação com o clima (Torres et al., 1997), com a classe de solo (Bertani et al., 2001; Costa \& Araújo, 2001) e com a fertilidade do solo (Lima et al., 2003). Poucos trabalhos consideram a importância da água na dinâmica da vegetação (Botrel et al., 2002; Martins et al., 2003; Dalanesi et al., 2004; Rocha et al., 2005), assim como são raros os que estudam a relação solo-vegetação, considerando a química, a granulometria e a disponibilidade de água ao longo do perfil do solo (Rossi et al., 2005).

O objetivo deste trabalho foi identificar atributos e classes de solos associados à ocorrência de remanescentes de cerrado e de floresta nativa em Campinas, SP, e identificar espécies indicadoras desses ambientes.

\section{Material e Métodos}

O estudo foi realizado no Município de Campinas, SP. Dos 27 fragmentos estudados, 23 encontram-se na bacia hidrográfica do Ribeirão das Anhumas, que drena parte dessa região, circunscrita pelas coordenadas $22^{\circ} 45^{\prime} 1$ " a $22^{\circ} 56^{\prime} 11^{\prime \prime S}$ e $46^{\circ} 58^{\prime} 42^{\prime \prime}$ a $47^{\circ} 7^{\prime} 1$ ' $\mathrm{W}$, e corresponde a uma superfície de 150,2 $\mathrm{km}^{2}$ (Torres et al., 2006). A Bacia do Anhumas apresenta $46 \%$ de sua área urbanizada. O clima regional é, segundo classificação de Köppen, mesotérmico de inverno seco (Cwa), com precipitação anual de $1.381 \mathrm{~mm}$, deficiência hídrica de $16,7 \mathrm{~mm}$ (junho-setembro), e excedente hídrico de $361,1 \mathrm{~mm}$ (novembro-março).

A área estudada se situa na transição entre o Planalto Atlântico e a Depressão Periférica Paulista e é constituída por relevos de colinas, na área da Depressão, e de morrotes, na área do Planalto (Yoshinaga \& Pires Neto, 1993). No Planalto Atlântico, a geologia da área de estudo tem predomínio de gnaisses e granitos, ao passo que na Depressão Periférica predominam rochas sedimentares (arenitos e diamictitos) associadas a intrusões de rochas básicas (Yoshinaga \& Pires Neto, 1993). No mapa de solos da Bacia do Anhumas (Torres et al., 2006), representativa da região estudada, predominam Latossolos (51\%) e Argissolos (41\%). O regime hídrico dos solos bem drenados é údico, ou seja, o solo fica seco (potencial matricial abaixo de $-1.500 \mathrm{kPa}$ ) por menos que 90 dias cumulativos (Soil Survey Staff, 1999).

Os solos dos fragmentos foram identificados inicialmente por sondagens com trado, e posteriormente foram descritos morfologicamente em trincheiras de $1 \mathrm{~m}$ de profundidade, complementadas por sondagem com trado, na base da trincheira, até $2 \mathrm{~m}$. Os solos foram classificados de acordo com o Sistema Brasileiro de Classificação de Solos (Santos et al., 2006). Em laboratório, foi realizada caracterização química, físico-hídrica e granulométrica das amostras dos horizontes A e B de cada fragmento. As amostras de solo foram avaliadas quimicamente, de acordo com método descrito por Camargo et al. (1986), para pH em água, $\mathrm{pH}$ em $\mathrm{KCl}, \mathrm{pH}$ em $\mathrm{CaCl}_{2}$, matéria orgânica (Método Walkley-Black), $\mathrm{Al}, \mathrm{Ca}, \mathrm{Mg}$ e $\mathrm{K}$ trocáveis, $\mathrm{P}$ disponível e acidez potencial $\left(\mathrm{H}^{+}+\mathrm{Al}^{3+}\right)$. A granulometria foi avaliada pelo método do densímetro, segundo Camargo et al. (1986). Os resultados alcançados nessas 
análises do solo compuseram um conjunto de variáveis descritoras do ambiente.

Foram coletadas amostras indeformadas, e analisada a retenção de água dos horizontes $\mathrm{A}$ e $\mathrm{B}$ dos solos de cada fragmento. Foi medida a capacidade de retenção de água da amostra saturada, em 0, 6, 10, 30, 100 e $1.500 \mathrm{kPa}$ pelo método da câmara de pressão (Cooper \& Vidal-Torrado, 2005), usando-se a média de três repetições. Os dados gerados foram tratados pelo programa SWRC versão 3.0 (Dourado Neto et al., 2002), utilizando-se o modelo de Van Genuchten (1980) que calculou os parâmetros $\theta \mathrm{s}, \theta \mathrm{r}, \mathrm{n}, \alpha$, utilizados na elaboração da curva de retenção de água, e que também compuseram a matriz de descritores ambientais.

As fisionomias dos 27 fragmentos estudados são apresentadas na Tabela 1, sendo cinco de cerrado (fragmentos 10, 11, 23, 24 e 27), uma de transição (fragmento 7) e 21 de floresta estacional. O levantamento florístico-fitossociológico foi realizado por meio do método de ponto-quadrante (Teixeira \& Rodrigues, 2006). Em cada fisionomia de fragmento, foram instalados 25 pontosquadrantes, com distância de $10 \mathrm{~m}$ entre pontos e perímetro à altura do peito (PAP) de $10 \mathrm{~cm}$ ou mais, como critério de inclusão. Assim, em cada fragmento ou fisionomia de fragmento amostraram-se 100 árvores.

A identificação das espécies foi realizada em campo, confirmando-se posteriormente as determinações por comparação com materiais depositados no herbário do Instituto Agronômico (IAC) ou com o auxílio da bibliografia pertinente. Os materiais-testemunha das espécies amostradas foram incorporados ao acervo do Herbário IAC. Os resultados obtidos foram tabulados e utilizados para a montagem da matriz de espécies, utilizando-se as espécies com maiores densidades. A análise de similaridade entre os fragmentos vegetais foi realizada com base na presença e ausência de espécie, usando-se índice de similaridade de Jaccard e média de grupo como método de ligação (Sanchez et al., 1999).

$\mathrm{Na}$ análise de correspondência canônica (CCA), os dados foram organizados em duas matrizes: uma de espécies e outra de variáveis ambientais. A primeira foi constituída pela densidade das espécies de cada fragmento, sendo selecionadas as espécies mais abundantes, com densidade igual ou superior a nove indivíduos por hectare. Espécies raras foram retiradas,

Tabela 1. Identificação, localização (UTM) e classificação da vegetação e dos solos dos fragmentos estudados ${ }^{(1)}$.

\begin{tabular}{|c|c|c|c|c|}
\hline № & Fragmento & Cord. UTM N/L & Vegetação $^{(1)}$ & Solo \\
\hline 1 & Condomínio Rio das Pedras & $7.476 .829 / 286.713$ & MESD & Latossolo Vermelho eutroférrico típico \\
\hline 2 & Jardim Miriam & $7.475 .945 / 291.295$ & MESD & Argissolo Vermelho Amarelo eutrófico abrúptico \\
\hline 3 & Bosque São José & $7.463 .610 / 290.215$ & MESD & Argissolo Vermelho Amarelo distrófico típico \\
\hline 4 & Bosque Chico Mendes & $7.471 .160 / 291.475$ & MESD & Argissolo Vermelho Amarelo distrófico nitossólico \\
\hline 5 & Bosque dos Italianos & $7.467 .675 / 287.400$ & MESD & Latossolo Vermelho distrófico típico \\
\hline 6 & Bosque dos Alemães & $7.467 .150 / 287.860$ & MESD & Latossolo Vermelho Amarelo distrófico típico \\
\hline 7 & Vila Holândia I & $7.480 .616 / 285.822$ & MT & Latossolo Vermelho Amarelo distrófico típico \\
\hline 8 & Bosque dos Jequitibás & $7.465 .000 / 289.800$ & MESD & Argissolo Vermelho Amarelo distrófico abrúptico \\
\hline 9 & Bosque da Paz & $7.291 .945 / 291.945$ & MESD & Nitossolo Háplico eutrófico típico \\
\hline 10 & Vila Holândia II & $7.480 .616 / 285.822$ & $\mathrm{C}$ & Latossolo Vermelho Amarelo distrófico típico \\
\hline 11 & Laboratório Síncrotron & $7.476 .912 / 289.580$ & $\mathrm{C}$ & Argissolo Vermelho distrófico latossólico \\
\hline 12 & Mata Santa Genebra & $7.474 .451 / 283.892$ & MESD & Argissolo Vermelho distrófico típico \\
\hline 13 & Sítio São Francisco & $7.475 .940 / 291.075$ & MESD & Argissolo Vermelho Amarelo eutrófico típico \\
\hline 14 & Parque Ecológico Mons. E.J. Salim & $7.465 .310 / 292.240$ & $\mathrm{MESD} / \mathrm{MC}$ & Neossolo Flúvico Tb distrófico típico \\
\hline 15 & Fazenda São Bento & $7.477 .600 / 292.840$ & MESD & Argissolo Vermelho Amarelo distrófíco latossólico \\
\hline 16 & Residencial Manacás & $7.479 .661 / 232.850$ & MESD & Nitossolo Vermelho eutroférrico latossólico \\
\hline 17 & Condomínio AlphaVille & $7.474 .671 / 291.694$ & MESD & Argissolo Vermelho Amarelo distrófico abruptico \\
\hline 18 & Condomínio Estância Paraíso I & $7.477 .059 / 290.362$ & MESD/MC & Argissolo Amarelo distrófico abrúptico \\
\hline 19 & Mata Santa Genebrinha & $7.473 .439 / 287.822$ & MESD & Argissolo Vermelho eutrófico típico \\
\hline 20 & Mata do Boi Falô & $7.472 .294 / 288.754$ & MESD & Cambissolo Háplico Tb eutrófico típico \\
\hline 21 & Fazenda Argentina I & $7.473 .669 / 289.461$ & MESD & Nitossolo Vermelho distróferrico latossolico \\
\hline 22 & Fazenda Argentina II & $7.475 .150 / 289.950$ & MESD & Latossolo Vermelho distroférrico típico \\
\hline 23 & Fazenda Santa Elisa Cerrado & $7.452 .281 / 277.485$ & $\mathrm{C}$ & Latossolo Amarelo distrófico típico \\
\hline 24 & Aeroporto de Viracopos & $7.452 .950 / 279.772$ & $\mathrm{C}$ & Latossolo Vermelho Amarelo distrófico típico \\
\hline 25 & Parque Xangrilá II & $7.477 .646 / 292.879$ & $\mathrm{MESD} / \mathrm{MC}$ & Latossolo Amarelo distrófico argissólico \\
\hline 26 & Fazenda Santa Elisa Mata & $7.469 .995 / 287.863$ & MESD & Latossolo Vermelho distrófico típico \\
\hline 27 & São Marcos & $7.472 .468 / 281.746$ & $\mathrm{C}$ & Cambissolo Haplico Tb eutroférrico léptico \\
\hline
\end{tabular}

(1)MESD, mata estacional semidecídua; C, cerrado; MC, mata ciliar; MT, mata estacional semidecídua com elementos de cerrado. 
pois apresentam pouca ou nenhuma influência nos resultados de ordenações (Nappo et al., 2000). A matriz de dados ambientais incluiu propriedades químicas, físicas e de retenção de água dos horizontes A e B dos solos, em adição à declividade, com um total de 48 variáveis.

O número de variáveis ambientais foi limitado pelo número de linhas da matriz, no caso o número de fragmentos (27). As matrizes foram normalizadas (Carvalho et al., 2005), divididas em dois grupos, de acordo com o horizonte de coleta da amostra (horizontes A e B), e selecionadas, eliminando-se as variáveis complementares e altamente correlacionadas de cada grupo. Em seguida, os dois grupos foram submetidos à análise prévia da CCA, selecionando-se as variáveis com correlação ponderada superior a 0,4 (Oliveira Filho et al., 1994; Rocha et al., 2005). As variáveis selecionadas foram unidas em um único grupo, ao qual se acrescentou a medida de declividade, e analisadas por CCA pelo programa FITOPAC 1.6 (Shepherd, 2006).

\section{Resultados e Discussão}

Dos 27 fragmentos estudados, cerca de $90 \%$ estão em solos profundos, sendo 37\% Latossolos e $40 \%$ Argissolos (Tabela 1). Dos cinco fragmentos de cerrado estudados, três estão sobre Latossolos, um sobre Cambissolo Háplico eutroferrico léptico (fragmento 27). Apenas o fragmento 11 está sobre Argissolo que, no entanto, apresenta horizonte latossólico logo abaixo do B textural. Os solos de cerrado, com exceção do fragmento 27 , são solos com baixa saturação por bases e elevada saturação por alumínio (distróficos e álicos). Esse resultado era esperado, já que a maioria dos solos sob cerrado ou sob cerradão são Latossolos distróficos com alta saturação por alumínio (Haridasan, 2000).

Os 2.700 indivíduos amostrados estão distribuídos em 64 famílias, com 262 espécies. No cerrado, foram encontradas 80 espécies, distribuídas em 37 famílias. As matas apresentaram 227 espécies em 61 famílias. A distribuição dos fragmentos no dendrograma de similaridade (Figura 1) colocou em lados opostos os fragmentos sobre solos com alto gradiente textural $(2,8,13$ e 17 -Argissolos), e os de baixo gradiente textural (10, 11, 23, 24 e 27 - Latossolos ou intermediários para
Latossolos). A ordenação no dendrograma, elaborado com dados florísticos, mostra que os Latossolos estão agrupados na parte superior e os Argissolos agrupados na parte inferior (Figura 1). Esta distribuição associa as matas aos maiores gradientes texturais no perfil do solo e a solos com horizontes B textural e B nítico.

Dos oito fragmentos mais próximos ao eixo do índice de similaridade, não há nenhum Latossolo: seis são Argissolos e dois Nitossolos, esses últimos, solos com

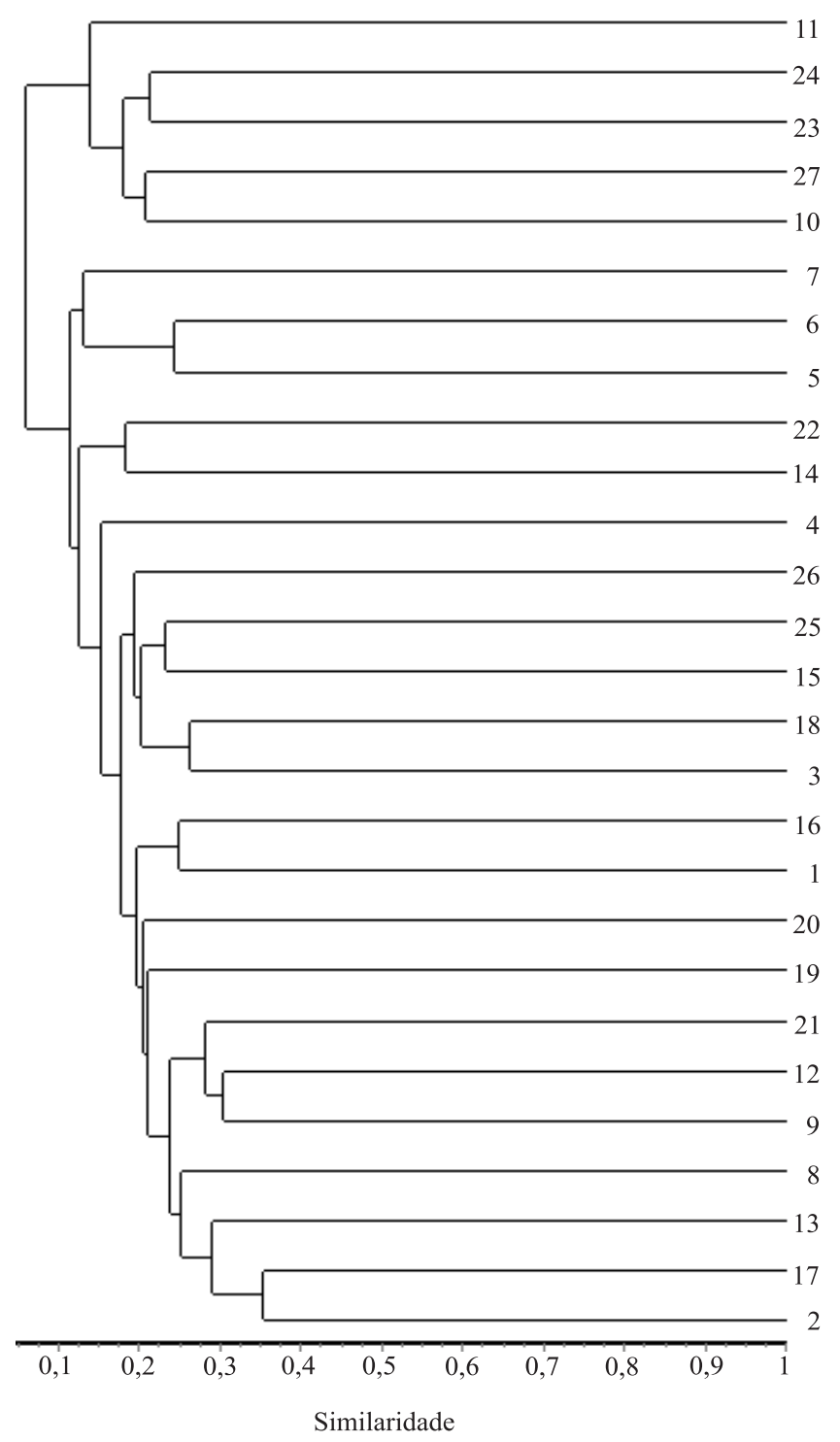

Figura 1. Dendrograma baseado na presença e ausência de espécies em 27 fragmentos do Município de Campinas, SP, elaborado pelo método de Jaccard, com média de grupo (UPGMA). 
estrutura, no mínimo, moderada em blocos, no horizonte B (Santos et al., 2006). Quanto ao aspecto morfológico, espera-se que solos com horizonte B com estrutura em blocos moderadamente desenvolvida, apresentem menor macroporosidade que os com estrutura granular, típica dos Latossolos estudados. Isso pode influenciar a movimentação e retenção da água nesses solos. Dos dez últimos fragmentos agrupados na parte superior do dendrograma, incluindo os cinco de cerrado, apenas três não são Latossolos: um Cambissolo háplico (27), um Neossolo flúvico (14) e um Argissolo latossólico (11) (Figura 1). Isso sugere que a similaridade florística observada entre os fragmentos é influenciada por propriedades utilizadas como critérios diagnósticos na classificação de solos, uma evidência da utilidade da classificação de solos (Santos et al., 2006) para estratificação de ambientes florísticos. Estrutura e presença ou não de gradiente textural, propriedades que diferenciam esses solos, estão relacionadas ao comportamento físicohídrico do perfil, especialmente à retenção de água pelo solo (Cooper \& Vidal-Torrado, 2005). Isto sugere que essas propriedades sejam responsáveis por essa estratificação.

A análise da relação solo-vegetação por correspondência canônica (Figura 2) mostra que 15 variáveis ambientais apresentaram correlação acima de $0,4 \mathrm{com}$ ao menos um dos dois primeiro eixos. Essas variáveis (Tabela 2) chegaram a explicar um total de $31,5 \%$ da variância global dos dados nos dois primeiros eixos, $22,2 \%$ no primeiro eixo e $9,3 \%$ no segundo. Essa baixa correlação (elevada variância remanescente) é esperada em ordenações de dados ecológicos, tendo em vista a complexidade dos fatores envolvidos na determinação da composição florística e estrutural de formações vegetais (Nappo et al., 2000; Dalanesi et al., 2004). Quanto aos eixos 1 e 2, os resultados foram significativos pelo teste de Monte Carlo a 0,05\%, tendo como autovalores, respectivamente, 0,55 e 0,23 .

Os fragmentos de mata sobre Argissolos estão concentrados na região central da Figura 2, o que mostra maior similaridade entre as espécies desses fragmentos e entre seus descritores ambientais. Os fragmentos de mata sobre Latossolos, Nitossolos e Cambissolos encontram-se mais dispersos. Isto reforça a relação dos solos com a vegetação encontrada também no dendrograma da vegetação (Figura 1). Apesar de a classificação dos solos não participar da matriz ambiental, as variáveis selecionadas apresentaram uma distribuição conforme o padrão das classes de solos, a exemplo do encontrado por Dalanesi et al. (2004).
Variáveis que apresentaram maiores correlações com o eixo 1, e distinguiram cerrado e mata, com correlação decrescente, foram: parâmetro $n$ da curva de retenção de água do horizonte $\mathrm{B}$ do solo (n-B), Ca do horizonte $\mathrm{A}$ (Ca-A), $\mathrm{H}+\mathrm{Al}(\mathrm{H}+\mathrm{Al}-\mathrm{A})$ e $\mathrm{Al}$ do horizonte $\mathrm{A}(\mathrm{Al}-\mathrm{A})$ (Figura 2). Esses resultados indicam estreita associação dos fragmentos de cerrado com a fertilidade do horizonte A e com o comportamento da água no horizonte B. A distribuição do cerrado associada a solos com baixa fertilidade e altos teores de Al concorda com outros autores (Haridasan, 2000; Rossi et al., 2005).

Os resultados da CCA sugerem uma dinâmica diferenciada da água do solo nos cerrados em relação às matas, especialmente com relação ao valor $\mathrm{n}$, macroporos, densidade e matéria orgânica, o que está de acordo com a ocorrência das matas preferencialmente nos Argissolos, e dos cerrados nos Latossolos. À exceção da matéria orgânica do solo, os demais parâmetros físicos e físico-hídricos refletem atributos

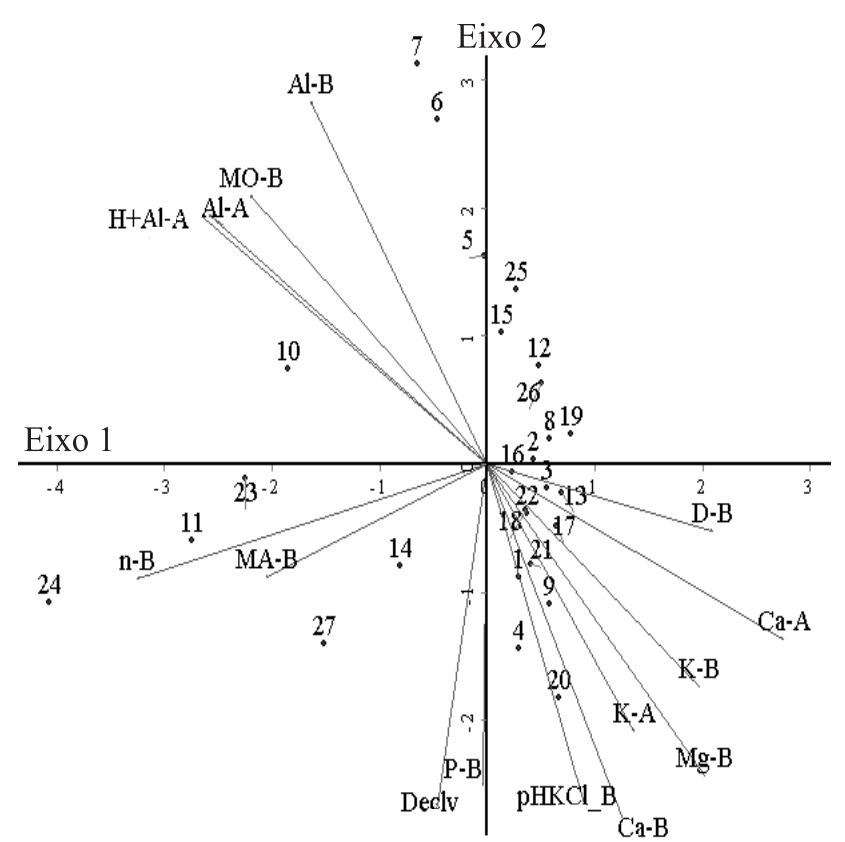

Figura 2. Análise de correspondência canônica dos fragmentos de vegetação nativa de Campinas, SP (identificados pelos números da Tabela 1), relacionando 15 variáveis ambientais com as espécies de maior densidade. Variáveis do horizonte A: Al-A, alumínio; $\mathrm{H}+\mathrm{Al}-\mathrm{A}$, acidez trocável; $\mathrm{K}-\mathrm{A}$, potássio; Ca-A, cálcio. Variáveis do horizonte B: MO-B, matéria orgânica; $\mathrm{P}-\mathrm{B}$, fósforo; Al-B, alumínio; K-B, potássio; Ca-B, cálcio; Mg-B, magnésio; Densi-B, densidade; MA-B, macroporos; n-B, parâmetro de ajuste das equações de Van Genuchten (1980); Declv, declividade. 
diagnósticos diferenciais entre horizontes $B$ texturais (Argissolos) e B latossólicos (Latossolos) (Cooper, 1999; Santos et al., 2006). A diferença de gradiente textural $\mathrm{e}$, mais especificamente, na estrutura do horizonte B desses dois tipos de solos pode, portanto, influenciar a diferenciação fisionômica da vegetação entre cerrado e mata.

No eixo 2 (Figura 2), as duas variáveis com maior correlação são o $\mathrm{Al}$ e o $\mathrm{Ca}$, ambas do horizonte $\mathrm{B}$ (Al-B e Ca-B). Isso mostra a influência da fertilidade do solo na distribuição da densidade de espécies entre os fragmentos, uma vez que as variáveis associadas ao eixo 2 não distinguem as fitofisionomias, mas estão associadas ao posicionamento diferenciado dos fragmentos dentro de uma mesma fisionomia vegetal. Isso indica que a fertilidade do solo e a toxidez do $\mathrm{Al}$ no horizonte $\mathrm{B}$ influenciam a composição das espécies também dentro das matas e dos cerrados, e diferencia um fragmento do outro. Ou seja, mesmo considerando uma mesma formação vegetal, a fertilidade do solo parece estar relacionada com a diversidade de espécies nos fragmentos, o que está de acordo com Lima et al. (2003), que identificaram grupos de espécies arbóreas em floresta tropical com base nos teores de $\mathrm{Ca}, \mathrm{Mg}, \mathrm{K}$ e $\mathrm{Al}$ trocáveis do solo.

Do total de espécies encontradas, 47 atingiram os critérios de seleção - densidade média igual ou superior a nove indivíduos por hectare - e compuseram a matriz de espécies (Tabela 3). Essas espécies apresentaram distribuição correlacionada com a matriz de dados ambientais (Figura 3). As quatro espécies com os maiores escores negativos com o eixo 1 são exclusivas dos fragmentos de cerrado (Figura 3). Luehea grandiflora está presente nos cinco fragmentos e Persea willdenovii em dois. Xylopia aromatica e Erythroxylum daphnites ocorreram somente em um fragmento de cerrado, com alta abundância de indivíduos no fragmento. Este fragmento (24) é o mais distante (cerca de $19 \mathrm{~km}$ ) da área núcleo do estudo, onde estão os outros 26 fragmentos. Fragmentos mais próximos e conectados tendem a ser mais semelhantes devido à possibilidade de troca gênica (Metzger, 1999) e, por isso, essa distância ou isolamento do fragmento Viracopos pode ter promovido diferenciação de espécies. Outro elemento que contribui para essa diferenciação florística é o solo do fragmento, em que

Tabela 2. Conjunto de 15 variáveis ambientais dos fragmentos, selecionadas pela análise de correspondência canônica (CCA), que possuem correlação acima de 0,4 com pelo menos um dos dois primeiros eixos da $\mathrm{CCA}^{(1)}$.

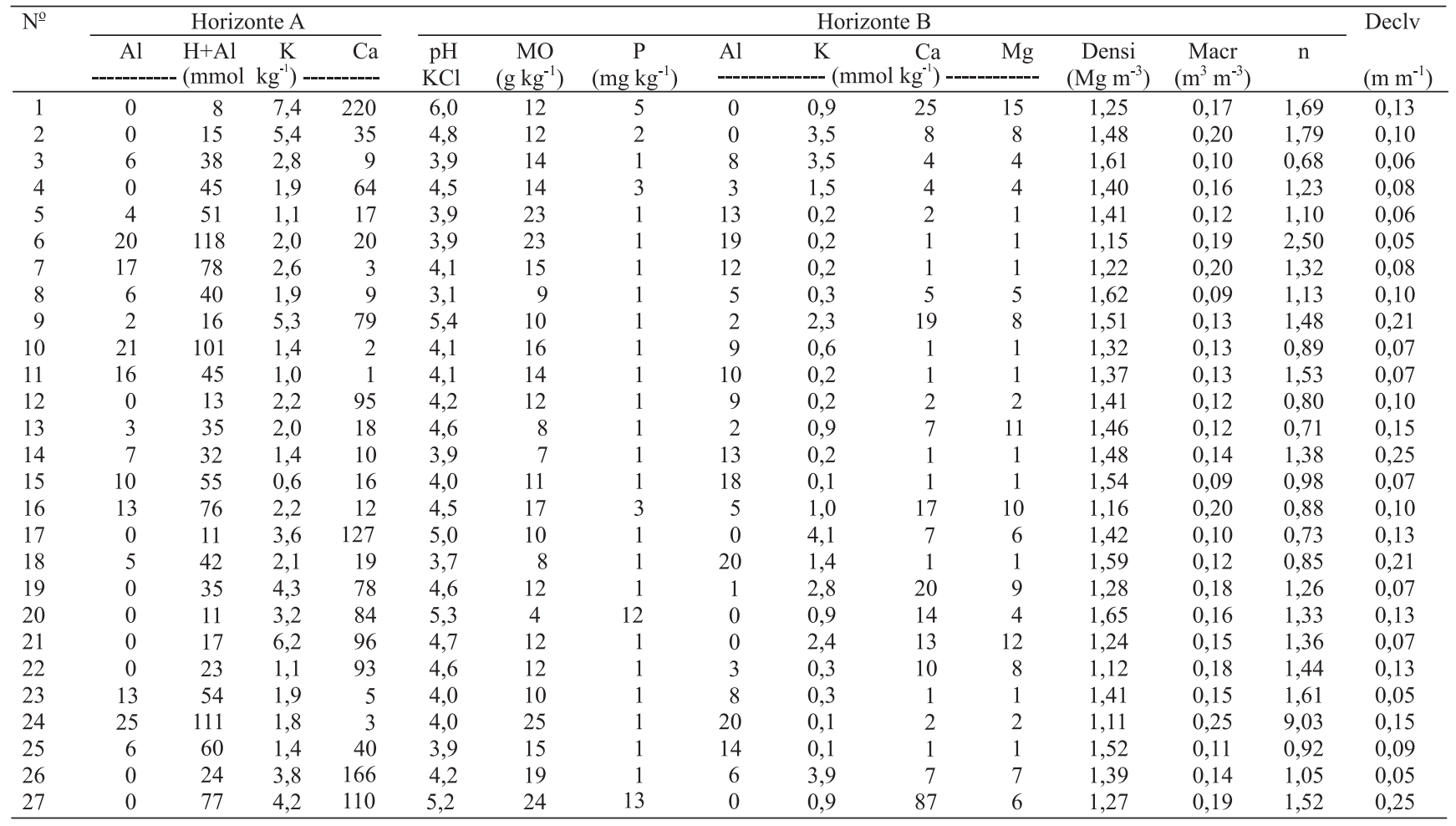

${ }^{(1)}$ MO, matéria orgânica; Densi, densidade; Macro, macroporos; n, parâmetro de ajuste das equações de Van Genuchten (1980); Declv, declividade. 
se destacam a baixa disponibilidade de $\mathrm{Ca}^{2+}$ e a alta concentração de $\mathrm{Al}^{3+}$ nos horizontes $\mathrm{A}$ e $\mathrm{B}$, e a baixa retenção de água, indicada por elevados valores de $\mathrm{n}$ e de macroporosidade, e reduzida densidade do solo. O cerrado de Viracopos possui abundância de indivíduos ausentes nos demais fragmentos de cerrado e é, assim, um fragmento de alta importância na região, a ser estudado e preservado.
Verifica-se (Figura 3) que o grupo de espécies que predominam (23 e 40) ou que somente ocorrem em cerrado $(18,28,37$ e 47$)$ tem elevada correlação com os parâmetros de solo n-B, H+Al-A, Al-B, MO-B e MA-B, em ordem de importância. Isto mostra que toxidez de $\mathrm{Al}$ e retenção de água são determinantes da ocorrência de espécies típicas no cerrado da região de estudo.

Tabela 3. Espécies selecionadas nos fragmentos do Município de Campinas, SP, que participaram da análise de correspondência canônica(1).

\begin{tabular}{|c|c|c|c|c|c|c|c|c|c|}
\hline \multirow[t]{2}{*}{$\mathrm{N}^{\mathrm{o}}$} & \multirow[t]{2}{*}{ Espécie } & \multicolumn{3}{|c|}{ Mata } & \multicolumn{3}{|c|}{ Cerrado } & \multicolumn{2}{|c|}{ Transição } \\
\hline & & ID & $\mathrm{Fr}$ & $\mathrm{D}$ & ID & $\mathrm{Fr}$ & $\mathrm{D}$ & ID & $\mathrm{D}$ \\
\hline 1 & Astronium graveolens Jacq. & 43 & 10 & 71,8 & 0 & 0 & 0 & 0 & 0 \\
\hline 2 & Actinostemon concepcionis (Chodat \& Hassl.) Hochr. & 71 & 10 & 128 & 0 & 0 & 0 & 1 & 11 \\
\hline 3 & Alchornea glandulosa Poepp. & 15 & 8 & 30,3 & 0 & 0 & 0 & 0 & 0 \\
\hline 4 & Aloysia virgata Juss. & 25 & 8 & 42,3 & 16 & 1 & 703 & 0 & 0 \\
\hline 5 & Aspidosperma polyneuron Müll.Arg. & 16 & 8 & 29,9 & 0 & 0 & 0 & 0 & 0 \\
\hline 6 & Cabralea canjerana (Vell.) Mart. & 22 & 11 & 32,2 & 0 & 0 & 0 & 0 & 0 \\
\hline 7 & Cariniana estrellensis (Raddi) Kuntze & 17 & 8 & 30,0 & 0 & 0 & 0 & 0 & 0 \\
\hline 8 & Casearia sylvestris Sw. & 45 & 12 & 55,9 & 24 & 3 & 203 & 0 & 0 \\
\hline 9 & Centrolobium tomentosum Guillemin ex Benth. & 43 & 15 & 41,5 & 0 & 0 & 0 & 0 & 0 \\
\hline 10 & Chrysophyllum gonocarpum Engl. & 35 & 12 & 49,8 & 0 & 0 & 0 & 0 & 0 \\
\hline 11 & Copaifera langsdorffii Desf. & 15 & 8 & 29,8 & 8 & 4 & 49 & 0 & 0 \\
\hline 12 & Cordia sellowiana .Cham & 8 & 5 & 26,8 & 8 & 3 & 55 & 0 & 0 \\
\hline 13 & Croton floribundus Spreng. & 34 & 10 & 64,0 & 0 & 0 & 0 & 0 & 0 \\
\hline 14 & Croton piptocalyx Müll.Arg. & 52 & 11 & 79,4 & 0 & 0 & 0 & 0 & 0 \\
\hline 15 & Cryptocarya aschersoniana Mez & 26 & 6 & 86,0 & 1 & 1 & 22 & 4 & 43 \\
\hline 16 & Cupania vernalis Cambess. & 25 & 12 & 31,0 & 0 & 0 & 0 & 0 & 0 \\
\hline 17 & Dendropanax cuneatum (DC.) Decne. \& Planch. & 21 & 8 & 38,5 & 0 & 0 & 0 & 0 & 0 \\
\hline 18 & Erythroxylum daphnites Mart. & 0 & 0 & 0 & 12 & 1 & 266 & 0 & 0 \\
\hline 19 & Esenbeckia febrifuga (A.St.-Hil.) A.Juss. ex Mart & 52 & 11 & 76,4 & 1 & 1 & 44 & 0 & 0 \\
\hline 20 & Esenbeckia leiocarpa Engl. & 20 & 6 & 56,7 & 0 & 0 & 0 & 0 & 0 \\
\hline 21 & Galipea jasminiflora (A.St.-Hil.) Engl. & 51 & 9 & 113 & 0 & 0 & 0 & 0 & 0 \\
\hline 22 & Gallesia integrifolia (Spreng.) Harms & 18 & 3 & 101 & 0 & 0 & 0 & 0 & 0 \\
\hline 23 & Gochnatia polymorpha (Less.) Cabrera & 8 & 1 & 134 & 30 & 5 & 136 & 0 & 0 \\
\hline 24 & Guarea macrophylla Vahl & 55 & 12 & 72,8 & 0 & 0 & 0 & 0 & 0 \\
\hline 25 & Guazuma ulmifolia Lam. & 23 & 11 & 30,3 & 0 & 0 & 0 & 0 & 0 \\
\hline 26 & Holocalyx balansae Micheli & 15 & 7 & 38,7 & 0 & 0 & 0 & 0 & 0 \\
\hline 27 & Luehea divaricata Mart. & 13 & 6 & 28,8 & 1 & 1 & 20 & 0 & 0 \\
\hline 28 & Luehea grandiflora Mart. & 0 & 0 & 0 & 42 & 5 & 167 & 0 & 0 \\
\hline 29 & Machaerium aculeatum Raddi & 12 & 6 & 29,2 & 8 & 2 & 165 & 0 & 0 \\
\hline 30 & Maclura tinctoria (L.) D.Don ex Steud. & 8 & 4 & 24,2 & 3 & 1 & 132 & 1 & 11 \\
\hline 31 & Metrodorea stipularis Mart. & 18 & 7 & 42,9 & 0 & 0 & 0 & 0 & 0 \\
\hline 32 & Mollinedia widgrenii A.DC. & 24 & 5 & 75,0 & 1 & 1 & 22 & 0 & 0 \\
\hline 33 & Myrcia splendens (.Sw.) DC & 15 & 7 & 36,1 & 5 & 1 & 111 & 4 & 43 \\
\hline 34 & Nectandra megapotamica (Spreng.) Mez & 39 & 14 & 45,7 & 0 & 0 & 0 & 0 & 0 \\
\hline 35 & Ocotea corymbosa (Meisn.) Mez & 20 & 4 & 81,5 & 0 & 0 & 0 & 7 & 76 \\
\hline 36 & Ocotea odorifera (Vell.) Rohwer & 16 & 8 & 37,2 & 1 & 1 & 11 & 1 & 11 \\
\hline 37 & Persea willdenovii Kosterm. & 0 & 0 & 0 & 13 & 2 & 144 & 0 & 0 \\
\hline 38 & Piper amalago $\mathrm{L}$. & 22 & 9 & 38,2 & 0 & 0 & 0 & 0 & 0 \\
\hline 39 & Piptadenia gonoacantha (Mart.) J.F.Macbr & 78 & 16 & 70,9 & 0 & 0 & 0 & 0 & 0 \\
\hline 40 & Platypodium elegans Vogel & 1 & 1 & 20,0 & 100 & 5 & 455 & 0 & 0 \\
\hline 41 & Sebastiania commersoniana (Baill.) L.B.Sm.\& Downs & 14 & 4 & 61,3 & 0 & 0 & 0 & 0 & 0 \\
\hline 42 & Siparuna guianensis Aubl. & 6 & 5 & 20,0 & 11 & 2 & 122 & 5 & 54 \\
\hline 43 & Trichilia catigua A.Juss. & 17 & 6 & 51,8 & 0 & 0 & 0 & 0 & 0 \\
\hline 44 & Trichilia claussenii C.DC. & 103 & 15 & 98,0 & 0 & 0 & 0 & 0 & 0 \\
\hline 45 & Trichilia pallida $\mathrm{Sw}$ & 57 & 17 & 55,7 & 4 & 1 & 88 & 0 & 0 \\
\hline 46 & Urera baccifera (L.) Gaudich. ex Wedd. & 23 & 5 & 57,4 & 0 & 0 & 0 & 0 & 0 \\
\hline 47 & Xylopia aromatica (Lam.) Mart. & 0 & 0 & 0 & 15 & 1 & 332 & 0 & 0 \\
\hline
\end{tabular}

${ }^{(1)} \mathrm{ID}$, número de indivíduos amostrados por fitofisionomia; Fr, número de fragmentos em que a espécie ocorre por fitofisionomia; D, densidade média nos fragmentos em que a espécie ocorre. 


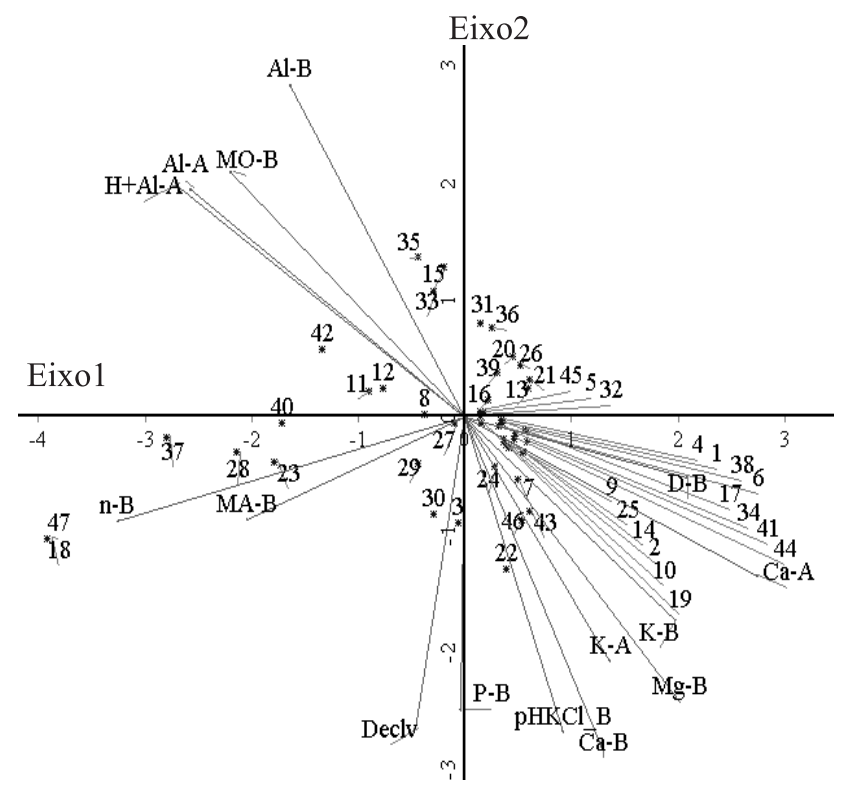

Figura 3. Análise de correspondência canônica das espécies de maior densidade (identificadas pelos números da Tabela 3) com variáveis ambientais nos fragmentos de vegetação nativa de Campinas, SP. Variáveis do horizonte A: Al-A, alumínio; H+Al-A, acidez trocável; K-A, potássio; Ca-A, cálcio. Variáveis do horizonte B: M.O-B, matéria orgânica; P-B, fósforo; Al-B, alumínio; K-B, potássio; $\mathrm{Ca}-\mathrm{B}$, cálcio; Mg-B, magnésio; Densi-B, densidade; MA-B, macroporos; n-B, parâmetro de ajuste das equações de Van Genuchten (1980); Declv, declividade.

Toxidez de $\mathrm{Al}$ como determinante de ocorrência de fisionomia de cerrado foi relatada por vários autores (Haridasan, 2000; Rossi et al., 2005; Ruggiero et al., 2006). Todavia, à exceção de Rossi et al. (2005), que encontraram associações do cerrado com a granulometria, atributos físicos e físico-hídricos de solos sob cerrado não estão entre os fatores apontados como determinantes da diferenciação cerrado-floresta. Há fortes evidências de que a ocorrência de fisionomia de cerrado na região é consequiência tanto da fertilidade quanto do comportamento hídrico do solo.

\section{Conclusões}

1. A classificação dos solos discrimina as fitofisionomias estudadas, com Argissolos mais associados às matas e Latossolos mais associados aos cerrados.

2. Baixa fertilidade, baixa retenção de água e drenagem acentuada favorecem a ocorrência de cerrado.

3. A barreira química ao maior desenvolvimento do sistema radicular imposta pelo excesso de alumínio e deficiência de cálcio no horizonte $\mathrm{B}$, associada à menor retenção de água nos solos sob cerrado, favorece o estabelecimento das espécies Luehea grandiflora, Xylopia aromatica, Erythroxylum daphnites e Persea willdenovii, abundantes e exclusivamente encontradas nos fragmentos de cerrado.

\section{Agradecimentos}

À Fapesp, pelo suporte financeiro; aos pesquisadores Michele de Sá Dechoum e Thiago Borges Conforti, pelo apoio na classificação e coleta da vegetação; ao Departamento de Parques e Jardins da Prefeitura Municipal de Campinas, pelo apoio nos trabalhos de campo; às estagiárias Analice Salina Espeleta, Ana Cristina Lorandi e Ariane Saldanha de Oliveira, pela colaboração.

\section{Referências}

BERTANI, D.F.; RODRIGUES, R.R.; BATISTA, J.L.F.; SHEPHERD, G.J. Análise temporal da heterogeneidade florística e estrutural em uma floresta ribeirinha. Revista Brasileira de Botânica, v.24, p.11-23, 2001.

BOTREL, R.T.; OLIVEIRA-FILHO, A.T.; RODRIGUES, L.A.; CURI, N. Influência do solo e topografia sobre as variações da composição florística e estrutura da comunidade arbóreo-arbustiva de uma floresta estacional semidecidual em Ingaí-MG. Revista Brasileira de Botânica, v.25, p.195-213, 2002.

CAMARGO, O.A. de; MONIZ, A.C.; JORGE, J.A.; VALADARES, J.M.A.S. Métodos de análise química, mineralógica e física de solos do Instituto Agronômico de Campinas. Campinas: Instituto Agronômico de Campinas, 1986. 94p. (Boletim Técnico, 106).

CARVALHO, D.A.; OLIVEIRA FILHO, A.T.; VILELA, E.A.; CURI, N.; BERG, E.V.D.; FONTES, M.A.L.; BOTEZELLI, L. Distribuição de espécies arbóreo-arbustivas ao longo de um gradiente de solos e topografia em um trecho de floresta ripária do Rio São Francisco em Três Marias, MG, Brasil. Revista Brasileira de Botânica, v.28, p.329-345, 2005.

COOPER, M. Influência das condições físico-hídricas nas transformações estruturais entre horizontes B latossólico e B textural sobre diabásio. 1999. 130p. Tese (Doutorado) Universidade de São Paulo, Piracicaba.

COOPER, M.; VIDAL-TORRADO, P. Caracterização morfológica, micromorfológica e físico-hídrica de solos com horizonte B nítico. Revista Brasileira de Ciência do Solo, v.29, p.581-595, 2005.

COSTA, A.A.; ARAÚJO, G.M. Comparação da vegetação arbórea de cerradão e de cerrado na Reserva do Panga, Uberlândia, Minas Gerais. Acta Botanica Brasilica, v.15, p.63-72, 2001. 
DALANESI, P.E.; OLIVEIRA-FILHO, A.T.; FONTES, M.A.L. Flora e estrutura do componente arbóreo da floresta do Parque Ecológico Quedas do Rio Bonito, Lavras, MG, e correlações entre a distribuição das espécies e variáveis ambientais. Acta Botanica Brasilica, v.18, p.737-757, 2004.

DOURADO NETO, D.; NIELSEN, D.R.; HOPMANS, J.W.; REICHARDT, K.; BACCHI, O.O.S. Software to model soil water retention curves (SWRC, version 2.00). Scientia Agricola, v.57, p.191-192, 2000.

HAFFER, J.; PRANCE, G.T. Impulsos climáticos da evolução na Amazônia durante o Cenozóico: sobre a teoria dos Refúgios da diferenciação biótica. Estudos avançados, v.16, p.175-206, 2002.

HARIDASAN, M. Nutrição mineral de plantas nativas do cerrado. Revista Brasileira de Fisiologia Vegetal, v.12, p.54-64, 2000.

KRONKA, F.J.N.; NALON, M.A.; MATSUKUMA, C.K. Inventário florestal da vegetação natural do Estado de São Paulo. São Paulo: Secretaria do Meio Ambiente; Instituto Florestal, 2005. 200p.

LIMA, J.A.S.; MENEGUELLI, N.A.; GAZEL FILHO, A.B.; PÉREZ, D.V. Agrupamento de espécies arbóreas de uma floresta tropical. Pesquisa Agropecuária Brasileira, v.38, p.109-116, 2003. MARTINS, S.V.; SILVA, N.R.S.S.; SOUZA, A.P.; MEIRA NETO, J.A.A. Distribuição de espécies arbóreas em um gradiente topográfico de Floresta Estacional Semidecidual em Viçosa, MG. Scientia Florestalis, n.64, p.172-181, 2003.

METZGER, J.P. Estrutura da paisagem e fragmentação: análise bibliográfica. Anais da Academia Brasileira de Ciências, v.71, p.445-463, 1999.

NAPPO, M.E.; OLIVEIRA FILHO, A.T.; MARTINS, S.V. A estrutura do sub-bosque de povoamentos homogêneos de Mimosa scabrella Bentham, em área minerada, em Poços de Caldas, MG. Ciência Florestal, v.10, p.17-29, 2000.

OLIVEIRA FILHO, A.T.; ALMEIDA, R.J.; MELLO, J.M.; GAVILANES, M.L. Estrutura fitossociológica e variáveis ambientais em um trecho da mata ciliar do córrego dos Vilas Boas, Reserva Biológica do Poço Bonito, Lavras (MG). Revista Brasileira de Botânica, v.17, p.67-85, 1994.

ROCHA, C.T.V.; CARVALHO, D.A.; FONTES, M.A.L. Community of trees of a continuum from swampy to upland forest in Coqueiral, SE, Brazil. Revista Brasileira de Botânica, v.28, p.203-218, 2005. ROSSI, M.; MATTOS, I.F.A.; COELHO, R.M.; MENK, J.R.F.; ROCHA, F.T.; PFEIFER, R.M.; MARIA, I.C. de. Relação solos/ vegetação em área natural no Parque Estadual de Porto Ferreira, São Paulo. Revista do Instituto Florestal, v.17, p.45-61, 2005.

RUGGIERO, P.G.C.; PIVELlO, V.R.; SPAROVEK, G.; TERAMOTO,E.; PIRES NETO, A.G. Relação entre solo, vegetação e topografia em área de cerrado (Parque Estadual de Vassununga, SP): como se expressa em mapeamentos? Acta Botanica Brasilis, v.20, p.383-394, 2006.

SANCHEZ, M.; PEDRONI, F.; LEITAO-FILHO, H.F.; CESAR, O. Composição florística de um trecho de floresta ripária na Mata Atlântica em Picinguaba, Ubatuba, SP. Revista Brasileira de Botânica, v.22, p.31-42, 1999.

SANTIN, D.A. A vegetação remanescente do município de Campinas, SP: mapeamento, caracterização fisionômica e florística visando a conservação. 1999. 467p. Tese (Doutorado) - Universidade Estadual de Campinas, Campinas.

SANTOS, H.G. dos; JACOMINE, P.K.T.; ANJOS, L.H.C. dos; OLIVEIRA, V.A. de; OLIVEIRA, J.B. de; COELHO, M.R.; LUMBRERAS, J.F.; CUNHA, T.J.F. (Ed.). Sistema Brasileiro de Classificação de Solos. 2.ed. Rio de Janeiro: Embrapa Solos, 2006. 306p.

SHEPHERD, G.J. Fitopac 1.6: manual do usuário. Campinas: Universidade Estadual de Campinas, 2006. 64p.

SOIL SURVEY STAFF. Soil Taxonomy: a basic system of soil classification for making and interpreting soil surveys. 2.ed. Washington, DC: USDA-NRCS, 1999. 869p. (Agriculture Handbook number 436).

TEIXEIRA, A.P.; RODRIGUES, R.R. Análise florística e estrutural do componente arbustivo-arbóreo de uma floresta de galeria no Município de Cristais Paulista, SP, Brasil. Acta Botanica Brasilica, v.20, p.803-813, 2006.

TORRES, R.B.; COSTA, M.C.; NOGUEIRA, F.P.; PERES FILHO, A. (Coord.). Recuperação ambiental, participação e poder público: uma experiência em Campinas, SP. Relatório de Pesquisa, 2006. Projeto de Pesquisa em Políticas Públicas (Processo Fapesp no. 01/02952-1). Disponível em: http://www.iac.sp.gov.br/ projetoanhumas. Acesso em: 10 abr. 2007.

TORRES, R.B.; MARTINS, F.R.; KINOSHITA, L.S. Climate, soil and tree flora relationships in forests in the state of São Paulo, southeastern Brasil. Revista Brasileira de Botânica, v.20, p.41-49, 1997.

VAN GENUCHTEN, M.T. A closed-form equation for predicting the hydraulic conductivity of unsaturated soils. Soil Science Society of America Journal, v.44, p.892-898, 1980.

VIADANA, A.G. A teoria dos refúgios florestais aplicada ao Estado de São Paulo. Rio Claro: Unesp, 2002. 72p.

YOSHINAGA, S.; PIRES NETO, A.G. (Coord.). Subsídios do meio físico-geológico ao planejamento do Município de Campinas (SP). São Paulo: Secretaria do Meio Ambiente do Estado de São Paulo, 1993. 217p. (Relatório técnico e mapas na escala 1:50.000).

Recebido em 20 de abril de 2007 e aprovado em 3 de agosto de 2007 